\title{
ACCELERATOR MASS SPECTROMETRY AT THE LUND PELLETRON ACCELERATOR
}

\section{GÖRAN SKOG}

Radiocarbon Dating Laboratory, University of Lund, S-22363 Lund, Sweden

\author{
RAGNAR HELLBORG and BENGT ERLANDSSON
}

Department of Physics, University of Lund, S-22362 Lund, Sweden

\begin{abstract}
Three years ago, funds were raised to equip the 3 MV Pelletron accelerator at the Department of Physics, Lund University for accelerator mass spectroscopy (AMS). We have modified the accelerator for mass spectroscopy by relocating focusing devices on both the low- and high-energy side of the accelerator and installing a Wien velocity filter and detectors for measuring the particle energy $(E)$ and energy loss $(\Delta E)$. We have been working exclusively with ${ }^{14} \mathrm{C}$ during the initial period. About 40 samples of elemental carbon have been produced, using $\mathrm{Fe}$ or $\mathrm{Co}$ as catalyst, during the last two years. The ${ }^{12} \mathrm{C}^{-}$current from these samples is about 3-5 $\mu \mathrm{A}$, using an ANIS sputtering source. We are now planning ${ }^{14} \mathrm{C}$ analyses in the fields of archaeology, Quaternary geology and radioecology.
\end{abstract}

\section{INTRODUCTION}

Since the start of the accelerator mass spectrometry (AMS) project in 1987, the Pelletron accelerator has been modified for AMS experiments. As a first step, we plan to use a light-ion $\left({ }^{10} \mathrm{Be},{ }^{14} \mathrm{C}\right)$ AMS system. During the initial period, we have been working exclusively with ${ }^{14} \mathrm{C}$, but we recently made the first ${ }^{10} \mathrm{Be}$ tests. We made ion-optical calculations, resulting in the modification of certain optical units, which has increased the transmission through the accelerator. We have included some new equipment, such as separate beam stops to monitor the ion current from masses 12 and 13 and a Wien velocity filter as the last unit along the experimental line to remove unwanted ions from the beam. Initially, carbon samples were prepared elsewhere, but during recent months, we have set up a chemical preparation line for the combustion and reduction of organic samples to elementary carbon.

\section{INSTRUMENTATION}

\section{Chemical Preparation}

The combined combustion and reduction system is outlined in Figure 1. The tubing is stainless steel with an inner diameter of $4 \mathrm{~mm}$. Quartz tubes with an inner diameter of $10 \mathrm{~mm}$ are used for the high-temperature parts of the system. The cold traps are Pyrex tubing. The combustion tube is sealed with a Viton O-ring, and the reduction oven is sealed with a teflon gasket. The quartz combustion tube can be replaced easily by a three-pipe construction of Pyrex tubing, which is used for carbonate samples. Carbonate and phosphoric acid are placed in separate legs and carbon dioxide is released by tilting the glass tube. The same technique is used at the AMS laboratory in Aarhus (Jan Heinemeier, personal communication 1987). Our reduction system is very similar to systems used at other laboratories (e.g., Vogel et al. 1984). The process, which usually takes less than $10 \mathrm{~h}$, starts with a $\mathrm{CO}_{2}$ pressure of about $500 \mathrm{mbar}$ and an $\mathrm{H}_{2}$ pressure of about 1800 mbar. Reduction is normally carried out at $600^{\circ} \mathrm{C}$. The catalyst is 325 mesh $99.99 \%$ iron powder contained in a well $2 \mathrm{~mm}$ in diameter and $1.0 \mathrm{~mm}$ deep, drilled in a copper cylinder $7 \mathrm{~mm}$ in diameter and $15 \mathrm{~mm}$ long. We have also tried cobalt as a catalyst, but the reduction time is almost twice as long as for iron. After the reduction process has been terminated, the carbon and iron powder mixture is pressed and the copper holder is placed in the ion source. 


\section{LUND PELLETRON LABORATORY}

\section{The combustion/reduction system}

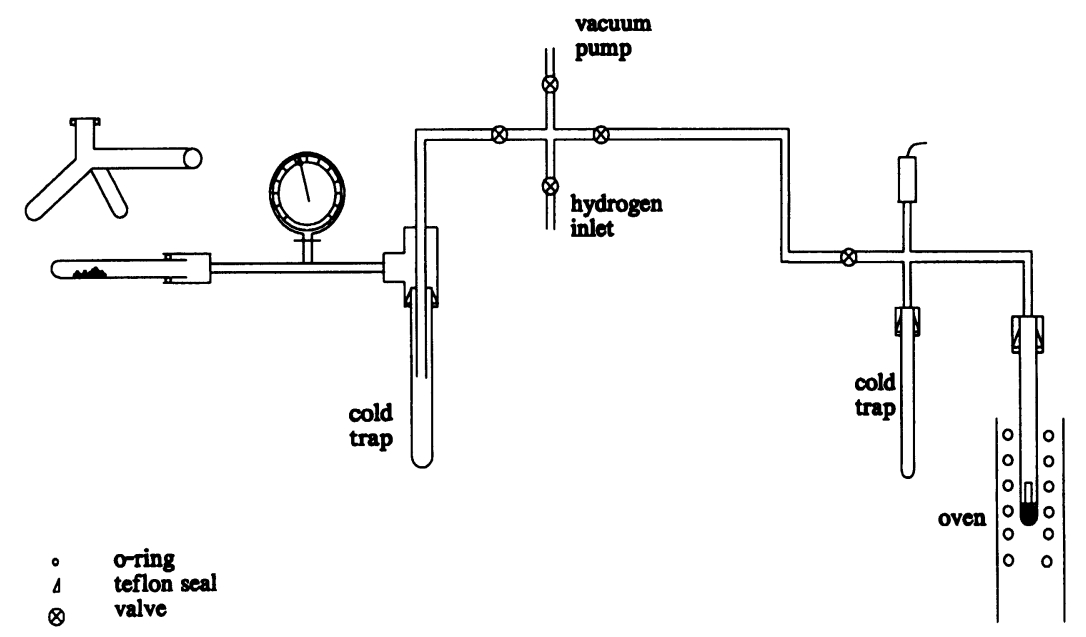

Fig. 1. Outline of the combustion and reduction system

\section{LUND PELLETRON LABORATORY}

\section{The AMS-facility}

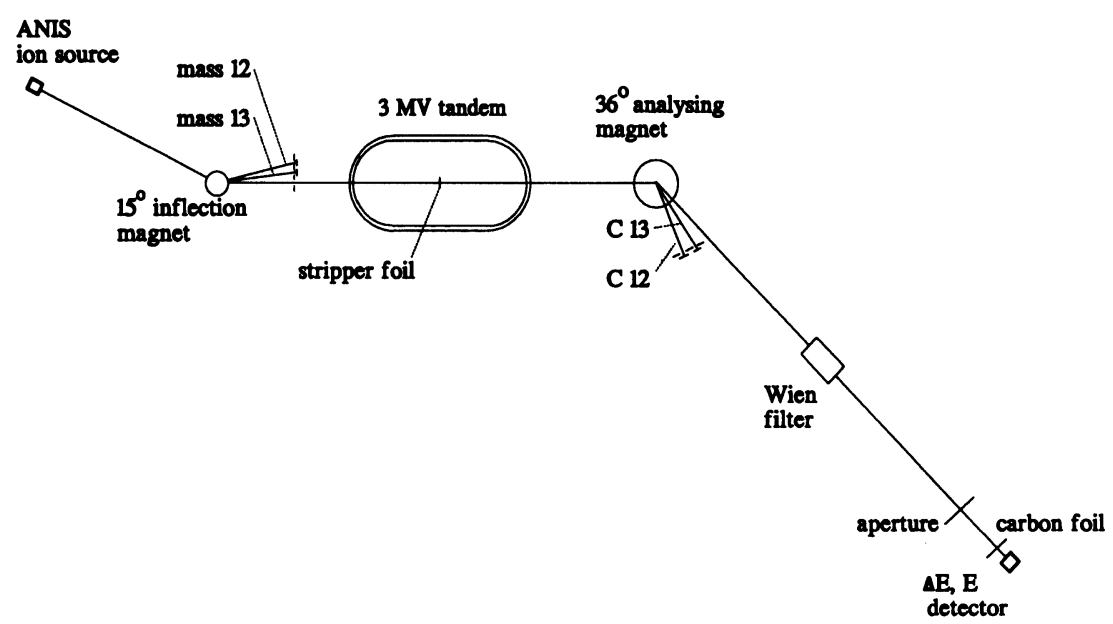

Fig. 2. A schematic layout of the AMS facility at the Lund Pelletron laboratory. The stripper foil thickness is $2 \mu \mathrm{g} \mathrm{cm}^{-2}$. In front of the detector are a carbon foil of $150 \mu \mathrm{g} \mathrm{cm}^{-2}$ and an aperture of $8 \mathrm{~mm} \times 20 \mathrm{~mm}$. The aperture prevents ions that are deflected by the Wien filter from reaching the detector. 


\section{The Accelerator Facility}

Figure 2 shows a schematic layout of the accelerator facility (a 3UDH Pelletron tandem accelerator). It consists of an ANIS sputter ion source, capable of delivering about $5 \mu \mathrm{A}^{12} \mathrm{C}^{-}$current. The $15^{\circ}$ inflection magnet is followed by beam stops for the detection of mass 12 and 13 when injecting mass 14 into the accelerator. In reconstructing the low-energy optics (Hellborg, Håkansson \& Skog 1990), we replaced all magnetic devices (except the inflection magnet) with electrostatic devices. We also installed new electrostatic steerers and profile monitors on the low-energy side. The accelerator is normally run at a terminal voltage of 2.7 MV during AMS experiments. Although a number of stripper foils of varying thickness are available (Tapper, Hellborg \& Malmqvist 1988), we usually use $2 \mu \mathrm{g} \mathrm{cm}{ }^{-2}$ carbon foils. The ${ }^{14} \mathrm{C}^{3+}$ component of the beam is selected by a $36^{\circ}$ analyzing magnet. Two beam stops after the analyzing magnet are positioned to measure the ${ }^{12} \mathrm{C}^{3+}$ and ${ }^{13} \mathrm{C}^{3+}$ currents for normalization of the ${ }^{14} \mathrm{C}^{3+}$ yield. We thus keep the analyzing magnet field constant during the measurements, and scan only the inflection magnet to measure the various carbon isotopes. After the beam is finally "cleaned" by the Wien velocity filter, it passes through a $150 \mu \mathrm{g} \mathrm{cm}^{-2}$ carbon foil before entering the detector system. The foil causes a suitable energy separation between the ${ }^{14} \mathrm{~N}$ and ${ }^{14} \mathrm{C}$ peaks, as shown in Figure 3A, B.

\section{MEASUREMENTS}

To date, we have made test measurements only with ${ }^{14} \mathrm{C}$ ions. We have produced about 40 samples, mostly from oxalic acid standards and from anthracite powder in order to measure the system background. The results of some of the measurements are shown in Figure 3A, B. We see from Figure $3 \mathrm{~A}$, which is a spectrum from an oxalic acid standard, that owing to different energy losses in the carbon foil, the ${ }^{14} \mathrm{C}$ and ${ }^{14} \mathrm{~N}$ peaks are well separated. In this spectrum, the ${ }^{14} \mathrm{~N}$ signal is relatively large, as the spectrum was taken a short time after the sample had been put into the ion source. Figure 3B shows the machine background with the ion source loaded with an unprocessed graphite sample of "dead" carbon. This spectrum was collected $24 \mathrm{~h}$ after loading the ion source, reducing the nitrogen signal considerably, and also lowering the ${ }^{14} \mathrm{C}$ background level. Some of the events between ${ }^{14} \mathrm{~N}$ and ${ }^{14} \mathrm{C}$ are probably due to ${ }^{13} \mathrm{C}$ ions that have been injected as $\mathrm{CH}^{-}$. The $\mathrm{CH}^{-}$ ions are broken up in the accelerator terminal, resulting in ${ }^{13} \mathrm{C}^{3+}$ ions entering the analyzing magnet with a final energy of $190 \mathrm{keV}$ less than that of the ${ }^{14} \mathrm{C}^{3+}$ ions. A few of these ${ }^{13} \mathrm{C}$ ions are scattered in the direction of the detector, which is probably the result of the small deflection angle for the analyzing magnet in our system. Most of the ${ }^{13} \mathrm{C}^{3+}$ ions, which are deflected in the direction of the detector, have higher energy than the ${ }^{14} \mathrm{C}^{3+}$ ions, but they are completely removed by the Wien filter. The number of ${ }^{14} \mathrm{C}$-events in Figure $3 \mathrm{~B}$ corresponds to a background level of $60 \mathrm{ka}$ $\mathrm{BP}$ when normalized to the number of events in the ${ }^{14} \mathrm{C}$-peak of the oxalic acid spectrum of Figure 3A. Unfortunately, we have not been able to reproduce the low background levels that we achieved with a graphite target when using anthracite processed in our reduction system. In fact, the background is too high for dating purposes. We have also tested one sample of dead graphite powder, that has been processed in the Uppsala graphitization system, but we found no significant lowering of the background level. This indicates that the high background is due to contamination by modern carbon in the ANIS source, where the iron-carbon mixture is situated near a hot plasma, rather than the graphitization process.

\section{CONCLUSIONS}

Three years have now passed since the initialization of the project and the first test measurements. We should be able to use the Pelletron accelerator as a useful tool for ${ }^{14} \mathrm{C}$ dating in 1 or 2 years. We have shown that the machine background is quite low and stability is good. During 1992, we 


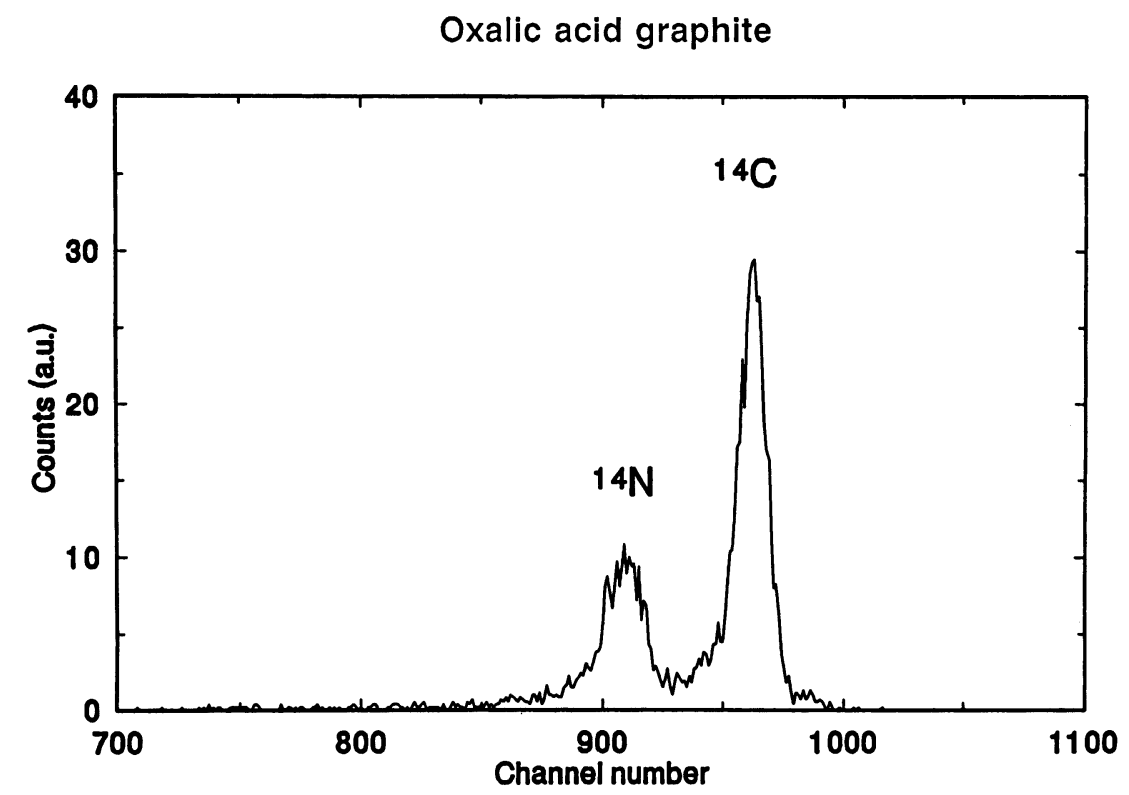

Fig. 3A. Energy spectrum for oxalic acid standard; a.u. = arbitrary unit

Anthracite graphite

Baking time: $24 \mathrm{~h}$

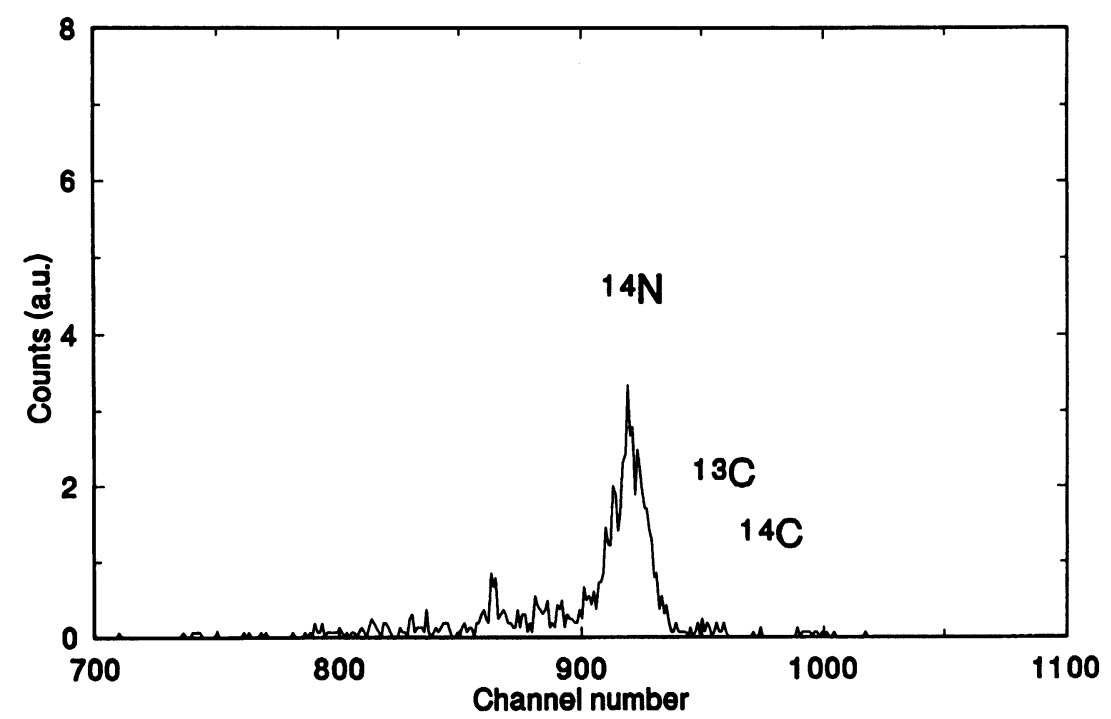

Fig. 3B. Energy spectrum for a graphite sample of "dead" carbon. The number of events in the ${ }^{14} \mathrm{C}$ peak is equivalent to a machine background of $c a .60 \mathrm{ka} \mathrm{BP}$. 
plan to replace the ANIS source with a cesium gun sputter ion source and to install a multisample holder. We also intend to install a computerized accelerator control system.

\section{REFERENCES}

Hellborg, R., Håkansson, K. and Skog, G. 1990 A new design of the low-energy optics of the Lund Pelletron accelerator. Nuclear Instruments and Methods A287: 161-165.

Tapper, U. A. S., Hellborg, R., and Malmqvist, K. G. 1988 Enhanced beam quality for proton microprobes using ultrathin stripper foils in tandem accelerators. Nuclear Instruments and Methods B34: 407-410.

Vogel, J. S., Southon, J. R., Nelson, D. E. and Brown, T. A. 1984 Performance of catalytically condensed carbon for use in accelerator mass spectrometry. In Wölfli, W., Polach, H. A. and Andersen, H. H., eds., Proceedings of the $3 \mathrm{rd}$ Conference on AMS. Nuclear Instruments and Methods 233(B5)(2): 289-293. 